\title{
Clinical Characteristics and Outcomes in Patients Undergoing Primary or Secondary Enucleation or Evisceration After Ocular Trauma
}

This article was published in the following Dove Press journal: Clinical Ophthalmology

\section{Angela C Gauthier (D) Oluseye K Oduyale (D) Michael J Fliotsos (D) \\ Sidra Zafar \\ Nicholas R Mahoney \\ Divya Srikumaran (D) \\ Fasika A Woreta (D)}

Wilmer Eye Institute, Johns Hopkins School of Medicine, Baltimore, MD, USA
Purpose: To investigate the frequency of primary versus secondary eye removal, frequency of enucleation versus evisceration, and characteristics and outcomes of patients undergoing these procedures after presenting with severe ocular trauma.

Patients and Methods: Retrospective chart review of patients presenting to the emergency department (ED) with severe eye trauma necessitating enucleation or evisceration between 2010 and 2018.

Results: There were 92 eyes from 90 patients included in our study. Twenty-seven percent of eyes underwent primary removal ( $n=25,14$ enucleation, 11 evisceration), while $73 \%$ of eyes underwent secondary removal ( $\mathrm{n}=67,50$ enucleation, 17 evisceration). The mean patient age was 45.2 years (range 4.2-92.6); primary enucleation/evisceration patients were older on average than secondary eye removal patients [53.8 years (range 15.9-91.2) versus 42.2 years (range 4.2-91.6 years), $\mathrm{p}=0.04$ ]. A median of 34 days passed between ED presentation and secondary enucleation/evisceration. Before undergoing secondary enucleation/evisceration, patients underwent a median of one ocular procedure (range $0-14$ ) for various complications of trauma including orbital infection, choroidal or retinal tear or detachment, and wound dehiscence. Open globe injury repairs comprised 43 of the 92 total procedures $(47 \%)$ performed prior to secondary enucleation/evisceration. Secondary enucleations/eviscerations required a median of seven clinic visits compared to two clinic visits required after primary surgeries $(p<0.01) .10 .7 \%$ of all patients $(n=10)$ had at least one implant-related complication following enucleation/evisceration, with all but one of these patients being in the secondary enucleation/evisceration group.

Conclusion: Primary enucleation or evisceration was performed in $27 \%$ of all eye removals, and enucleation was performed in $69.6 \%$ of all eye removals. Future research is warranted to determine if primary eye removal may be appropriate and when to consider enucleation versus evisceration.

Keywords: evisceration, enucleation, open globe repair, traumatic eye injury

\section{Introduction}

Eye injuries due to ocular trauma are a major cause of vision loss in the United States, with up to one-third of serious ocular injuries leading to eventual blindness. ${ }^{1}$ Traumatic injuries have been associated with long-term sequelae, including reduced quality of life and loss of productivity for patients. $^{2-4}$ Severe and devastating injuries may ultimately require removal of the affected eye with enucleation or evisceration. When patients arrive at the emergency department (ED) with no light perception, the ophthalmologist must decide whether to proceed with surgeries to
Wilmer Eye Institute, Johns Hopkins School of Medicine 600 North Wolfe Street, Baltimore, MD 21205, USA

Tel + | 4|0-96|-2868

Fax + | 4|0-6I4-9632

Email fworetal@jhmi.edu 
salvage the eye or consider primary enucleation or evisceration. Previous studies have examined the epidemiology and clinical features of severe ocular injury. ${ }^{1,5-11}$ Though the Ocular Trauma Score predicts visual potential and has been employed to assist in the management of ocular trauma, there are currently no definitive guidelines on when primary enucleation/evisceration should be considered. ${ }^{12-15}$ In this study, we investigate the clinical characteristics, demographics, and outcomes of a cohort of patients with severe eye trauma presenting to a tertiary care eye trauma center requiring eye removal. By presenting this data, as well as establishing the frequency of enucleation and evisceration in this patient population, we aim to provide useful information for ophthalmologists caring for patients with traumatic eye injuries.

\section{Patients and Methods}

We conducted a single-center, retrospective cohort study of patients who presented to the Eye Trauma Center at the Wilmer Eye Institute (WEI) of the Johns Hopkins Hospital $(\mathrm{JHH})$ in Baltimore, Maryland. This study adhered to the tenants of the Declaration of Helsinki and was approved by the Johns Hopkins Institutional Review Board (IRB). A waiver for written informed consent was granted by the IRB for the purposes of this study. The study was deemed compliant with the Health Insurance Portability and Accountability Act (HIPAA) by the IRB.

The WEI operates in the adult and pediatric ED's of the $\mathrm{JHH}$, a tertiary academic medical center in Baltimore, Maryland, and it is a designated eye trauma center in the region. An electronic chart review was conducted on all patients who presented to the ED with severe eye trauma requiring eventual enucleation or evisceration between January 2010 and June 2018. We identified enucleation and evisceration procedures using Current Procedural Termini (CPT) codes for removal of eye contents (65091, 65093, 65103, and 65105) provided by accessing a billing database of all surgeries performed. ${ }^{16}$ We then excluded patients who did not initially present with ocular trauma to our ED, such as patients with a blind painful eye for reasons other than trauma. Information about initial presentation and patient characteristics including medical comorbidities was collected. Comorbidities collected included diabetes, HIV, COPD, asthma, chronic kidney disease, chronic liver disease, heart disease, autoimmune diseases, dementia, and psychiatric disorders.

We defined primary enucleation/evisceration as surgery occurring within 24 hours of presentation, while secondary enucleation/evisceration was defined as surgery occurring after the first 24 hours of presentation. To assess patient outcomes, information regarding the date of last followup, number of clinic visits, number of ocular surgeries prior to secondary enucleation or evisceration, and complications requiring additional medical or procedural intervention during the study period were collected. Complications before secondary eye removal included endophthalmitis, retinal detachment, and wound dehiscence. Complications following eye removal included infection, migration, exposure, or extrusion of the intraorbital implant.

For statistical analysis, we performed Chi-square testing for differences in proportions of categorical variables, the Student's $t$-test for difference of means between groups, and Mood's median test for differences of medians between groups. Mann-Whitney non-parametric testing was used to compare the number of non-ocular medical comorbidities, as this data point was not normally distributed, and Kruskal-Wallis testing compared patient age stratified by race. Statistical analysis was performed using Stata version 13.0 (StataCorp, College Station, TX, USA). For the purposes of our statistical analysis, significance was defined as $p<0.05$.

\section{Results}

Baseline demographics and clinical characteristics of patients included in our study are demonstrated in Table 1. The majority of patients were male $(72.8 \%, \mathrm{n}=67)$. Black patients comprised $47.8 \%(\mathrm{n}=44)$ of the study population, followed by white $(43.5 \%, \mathrm{n}=40)$ and Hispanic $(7.6 \%, \mathrm{n}=7)$ patients, respectively. Patients presented at a mean age of 45.2 years (range $4.2-92.6$ years). The median age of eye removal patients was 30 for blacks (range 15-88), 54 for whites (range 4-91), 45 for Hispanics (26-58), and 46 for unknown/other; differences in patient age were statistically significant when stratified by race (H statistic 7.1, $\mathrm{p}=0.03$ ).

We identified 409 enucleation and evisceration procedures performed between 2010 and 2018, out of which a total of 92 eyes in 90 patients were removed following presentation in our ED for ocular trauma specifically. Enucleations comprised 14 of the 25 primary procedures $(56.0 \%)$ and 50 of the 67 secondary procedures $(74.6 \%$; $\mathrm{p}=0.08$ ). Patients who underwent primary eye removal were on average older (mean 53.8 years, range 15.9-91.2 years) than patients who underwent secondary eye removal (mean 42.2 years, range 4.2-92.6 years, 
Table I Characteristics of Patients Undergoing Enucleation/Evisceration After Trauma

\begin{tabular}{|c|c|c|c|c|}
\hline & $\begin{array}{l}\text { Total Eyes } \\
(n=92)\end{array}$ & $\begin{array}{l}\text { Primary Enucleation/ } \\
\text { Evisceration }(n=25)\end{array}$ & $\begin{array}{l}\text { Secondary Enucleation/ } \\
\text { Evisceration }(n=67)\end{array}$ & p-value \\
\hline $\begin{array}{l}\text { Procedure, n (\%) } \\
\text { - Enucleation } \\
\text { - Evisceration }\end{array}$ & $\begin{array}{l}64(69.6) \\
28(30.4)\end{array}$ & $\begin{array}{l}14(56.0) \\
11(44.0)\end{array}$ & $\begin{array}{l}50(74.6) \\
17(25.4)\end{array}$ & 0.08 \\
\hline $\begin{array}{l}\text { Sex, n (\%) } \\
\text { - Male } \\
\text { - Female }\end{array}$ & $\begin{array}{l}67(72.8) \\
25(27.2)\end{array}$ & $\begin{array}{l}17(68.0) \\
8(32.0)\end{array}$ & $\begin{array}{l}50(74.6) \\
17(25.4)\end{array}$ & 0.53 \\
\hline $\begin{array}{l}\text { Laterality, n (\%) } \\
\text { - Right } \\
\text { - Left }\end{array}$ & $\begin{array}{l}56(60.9) \\
36(39.1)\end{array}$ & $\begin{array}{l}16(64.0) \\
9(36.0)\end{array}$ & $\begin{array}{l}40(59.7) \\
27(40.3)\end{array}$ & 0.71 \\
\hline Age, mean years (S.D.) & $45.2(21.3)$ & $53.8(25.6)$ & $42.2(19.1)$ & $0.04 *$ \\
\hline $\begin{array}{l}\text { Race, n (\%) } \\
\text { - Black } \\
\text { - White } \\
\text { - Hispanic } \\
\text { - Other/unknown }\end{array}$ & $\begin{array}{l}44(47.8) \\
40(43.5) \\
7(7.6) \\
I(I . I)\end{array}$ & $\begin{array}{l}\text { II }(44.0) \\
\text { II }(44.0) \\
2(8.0) \\
\text { I }(4.0)\end{array}$ & $\begin{array}{l}33(49.2) \\
29(43.3) \\
5(7.5) \\
0(0.0)\end{array}$ & 0.42 \\
\hline Number of comorbidities, mean (S.D.) & $0.5 \mathrm{I}(0.9)$ & $0.60(1.0)$ & $0.48(0.8)$ & 0.76 \\
\hline
\end{tabular}

Note: *Denotes significance at the $p<0.05$ level.

Abbreviation: S.D., standard deviation.

$\mathrm{p}=0.04)$. There were no significant differences between the two groups for sex $(\mathrm{p}=0.53)$ or race $(\mathrm{p}=0.42)$. There was no significant difference regarding the number of medical comorbidities between the primary and secondary eye removal groups $(\mathrm{p}=0.76)$.

The etiologies of trauma in cases requiring enucleation/ evisceration surgery are presented in Table 2 . The most common diagnoses at presentation included open globe injuries $(88.0 \%, \mathrm{n}=81)$, chemical injuries $(3.3 \%, \mathrm{n}=3)$, avulsions/subluxations $(2.2 \%, \mathrm{n}=2)$, and other injuries including traumatic optic neuropathy and phacolytic glaucoma $(6.5 \%, n=6)$. Assault was the most common mechanism of eye injury in our cohort $(20.7 \%, \mathrm{n}=19)$, followed by gunshots $(17.4 \%, \mathrm{n}=16)$, falls $(17.4 \%, \mathrm{n}=16)$, workplace accidents $(14.1 \%, \mathrm{n}=13)$, and recreational accidents $(4.3 \%$, $\mathrm{n}=4)$. A greater proportion $(70.4 \%, \mathrm{n}=31)$ of blacks experienced non-accidental trauma (gunshots and assaults) compared to whites $(20 \%, n=8)$ and Hispanics $(0 \%, n=0$; $\mathrm{p}<0.001)$. Most eyes were removed due to being blind and painful $(95.7 \%, \mathrm{n}=88)$, followed by cosmetic disfiguration $(3.2 \%, \mathrm{n}=3)$, and endophthalmitis $(1.1 \%, \mathrm{n}=1)$.

The majority of patients undergoing enucleation or evisceration had no light perception (NLP) vision on presentation to the ED $(68.5 \%, n=63)$. Eighty-four percent of patients undergoing primary eye removal had NLP on presentation.
In the four cases where primary enucleation/evisceration was performed in a patient with greater than NLP vision $(n=3$ with light perception [LP] vision and $n=1$ with hand motion $[\mathrm{HM}]$ vision), the reason for pursuing surgery was extremely poor visual prognosis due to the severity of the injury, such as expulsed intraocular contents. In addition, two of these patients were elderly with comorbid dementia and cardiac conditions, increasing their surgical risk. After discussion with the patient and their families, the decision for primary enucleation was made. Of the patients who underwent secondary eye removal, $62.7 \%(\mathrm{n}=42)$ initially presented with NLP vision, $20.9 \%(n=14)$ eventually worsened to NLP vision prior to surgery, and $16.4 \%(\mathrm{n}=11)$ had greater than NLP vision at the time of surgery. Reasons for pursuing secondary enucleation/evisceration in patients with greater than NLP vision included intractable pain $(91 \%, n=10)$ and cosmetic disfigurement $(9 \%, n=1)$.

Clinical outcomes of cases requiring enucleation/evisceration surgery are shown in Table 3 . The median duration of follow-up after the initial presentation for all cases was 292 days (range 2-3411 days). The primary eye removal group had a median follow-up duration of 45 days (range 2-2187 days) while the secondary eye removal group had a median follow-up duration of 78 days (range 13-3411, $\mathrm{p}=0.002$ ). The median number of follow-up visits relating 
Table 2 Etiology of Trauma in Patients Undergoing Enucleation/Evisceration Surgery

\begin{tabular}{|c|c|c|c|c|}
\hline & $\begin{array}{l}\text { Total Eyes } \\
(n=92)\end{array}$ & $\begin{array}{l}\text { Primary Enucleation/ } \\
\text { Evisceration }(n=25)\end{array}$ & $\begin{array}{l}\text { Secondary Enucleation/ } \\
\text { Evisceration }(n=67)\end{array}$ & p-value \\
\hline $\begin{array}{l}\text { Diagnosis at presentation, n (\%) } \\
\text { - Open globe } \\
\text { - Chemical injury } \\
\text { - Avulsion/subluxation } \\
\text { - Other }\end{array}$ & $\begin{array}{l}81(88.0) \\
3(3.3) \\
2(2.2) \\
6(6.5)\end{array}$ & $\begin{array}{l}24(96.0) \\
0(0.0) \\
I(4.0) \\
0(0.0)\end{array}$ & $\begin{array}{l}57(85.1) \\
3(4.5) \\
1(1.5) \\
6(9.0)\end{array}$ & 0.77 \\
\hline $\begin{array}{l}\text { Cause of trauma, n (\%) } \\
\text { - Assault } \\
\text { - Gunshot wound } \\
\text { - Fall } \\
\text { - Workplace accident } \\
\text { - Recreational accident } \\
\text { - Other }\end{array}$ & $\begin{array}{l}19(20.7) \\
16(17.4) \\
16(17.4) \\
13(14.1) \\
4(4.4) \\
24(26.0)\end{array}$ & $\begin{array}{l}4(16.0) \\
4(16.0) \\
6(24.0) \\
0(0.0) \\
1(4.0) \\
10(40.0)\end{array}$ & $\begin{array}{l}15(22.4) \\
12(17.9) \\
10(14.9) \\
13(19.4) \\
3(4.5) \\
14(20.9)\end{array}$ & 0.12 \\
\hline $\begin{array}{l}\text { Visual acuity at presentation, } \mathrm{n}(\%) \\
\text { - NLP } \\
\text { - } \geq \mathrm{LP}\end{array}$ & $\begin{array}{l}63(68.5) \\
29(31.5)\end{array}$ & $\begin{array}{l}21(84.0) \\
4(16.0)\end{array}$ & $\begin{array}{l}42(62.7) \\
25(37.3)\end{array}$ & 0.05 \\
\hline $\begin{array}{l}\text { Reason for eye removal, n (\%) } \\
\text { - Pain } \\
\text { - Cosmetic disfigurement } \\
\text { - Endophthalmitis }\end{array}$ & $\begin{array}{l}88(95.7) \\
3(3.2) \\
1(1.1)\end{array}$ & $\begin{array}{l}24(96.0) \\
\mathrm{I}(4.0) \\
0(0.0)\end{array}$ & $\begin{array}{l}64(95.5) \\
2(3.0) \\
1(1.5)\end{array}$ & 0.67 \\
\hline
\end{tabular}

Abbreviations: NLP, no light perception; LP, light perception.

to the eye trauma for all cases was 5, with patients who had primary enucleation/evisceration following up a median of 2 times (range 1-10) and patients with secondary enucleation/ evisceration following up a median of 7 times (range 1-48, $\mathrm{p}<0.01)$.

The median time between presentation and secondary enucleation/evisceration was 34 days (range 2-3628 days). There were $23.9 \%(\mathrm{n}=16)$ cases of secondary enucleation/ evisceration that had at least one ocular complication (range 0-11 complications) prior to enucleation/evisceration. There were no cases of sympathetic ophthalmia in our cohort. A total of 93 procedures were performed prior to 62 cases of secondary enucleation/evisceration in our cohort (median 1 procedure, range $0-14$ procedures). The most common procedures included open globe injury repairs $(46.7 \%)$ and retinal tear/detachment repairs
(17.4\%). A complete list of all procedures performed prior to eye removal is shown in Table 4.

There was a median of one procedure (range 0-6) after secondary enucleation/evisceration due to an implantrelated complication. Of all 92 cases of enucleation/evisceration, $10.7 \%(\mathrm{n}=10)$ had at least one implant-related complication after the surgery (range 1-5). These complications included infection, extrusion, or migration of the orbital implant. One patient (4\%) in the primary eye removal group experienced an implant-related complication versus nine patients (13.4\%) in the secondary eye removal group $(\mathrm{p}=0.20)$.

\section{Discussion}

Our investigation sought to examine the frequency of primary versus secondary eye removal in a cohort of

Table 3 Clinical Outcomes of Patients Undergoing Enucleation/Evisceration Surgery

\begin{tabular}{|c|c|c|c|c|}
\hline & $\begin{array}{l}\text { Total Eyes } \\
(n=92)\end{array}$ & $\begin{array}{l}\text { Primary Enucleation/ } \\
\text { Evisceration }(n=25)\end{array}$ & $\begin{array}{l}\text { Secondary Enucleation/ } \\
\text { Evisceration }(n=67)\end{array}$ & p-value \\
\hline Duration of follow-up, median days (S.D.) & $292(830)$ & $45(5 \mid 4)$ & $78(885)$ & $0.002 *$ \\
\hline Number of follow-up visits, median (range) & $5(I-48)$ & $2(1-10)$ & $7(1-48)$ & $<0.0 I^{*}$ \\
\hline
\end{tabular}

Note: *Denotes significance at the $p<0.05$ level.

Abbreviation: S.D., standard deviation. 
Table 4 Procedures Received Prior to Secondary Enucleation/ Evisceration Surgery

\begin{tabular}{|l|l|}
\hline Procedure & Frequency (\%) \\
\hline Open globe repair & $43(46.7)$ \\
Retinal tear/detachment repair & $16(17.4)$ \\
Eyelid/brow repair & $7(7.6)$ \\
Conjunctivoplasty & $6(6.5)$ \\
Glaucoma surgery & $5(5.4)$ \\
Keratoplasty & $4(4.3)$ \\
Tarsorrhaphy & $4(4.3)$ \\
Orbital exploration & $1(1.1)$ \\
Exam under anesthesia & $1(1.1)$ \\
Lensectomy & $1(1.1)$ \\
Silicone oil removal & $1(1.1)$ \\
Orbital fracture repair & $1(1.1)$ \\
Intravitreal antibiotic injection & $1(1.1)$ \\
Band keratopathy repair & $1(1.1)$ \\
Total & $92(100 \%)$ \\
\hline
\end{tabular}

patients who eventually required eye removal due to severe trauma and to determine how often enucleation is performed compared to evisceration. Our secondary goal was to assess patient demographics, mechanisms of trauma, clinical outcomes, and complications following eye removal. This descriptive study can help ophthalmologists understand the most common presenting characteristics in patients with eye trauma severe enough to warrant removal in addition to the complications patients can experience before and after primary or secondary eye removal.

We found that assaults were the most prevalent etiology of ocular trauma in our cohort and that the majority of patients were male (72\%). In the literature, men also represent the majority of patients with ocular trauma. ${ }^{1,5,6,15,17}$ Non-accidental trauma, including gunshots and assaults, was more common in blacks (70.4\%) than whites (20\%) and Hispanics (0\%). Blacks also experienced ocular trauma at a younger median age (30 years) than whites (54 years) and Hispanics (45 years). These differences likely reflect the racial disparities affecting our patient population.

Our study found that primary eye removals occurred less frequently than secondary eye removals. One factor that was associated with primary enucleation/evisceration was increased age. There are a number of reasons why this may be possible, with the most obvious being the risk of subjecting elderly patients to multiple procedures under general anesthesia. ${ }^{18}$ In addition, younger patients may have more years for potential visual recovery than older patients, which may contribute to the treating physician's decision to not pursue primary enucleation/evisceration.

In our cohort, the majority of patients undergoing primary enucleation/evisceration presented with NLP vision. Retrospective studies examining outcomes of open globe injury repairs in patients with NLP vision after injury found that between $16 \%$ and $33 \%$ of eyes regained some vision following the surgery, ${ }^{10,19-21}$ and one study found that $14 \%$ of patients had a final visual acuity of between $20 / 50$ and 20/200. ${ }^{19}$ In our study, $58 \%$ $(n=25)$ of patients who underwent open globe injury repairs presented with NLP vision, and none of them regained vision after the repair. However, our study population is comprised of patients who underwent eventual eye removal, so the severity of injury is likely greater than that reported in these previous studies. The existence of a relative afferent pupillary defect (RAPD), wound extending posterior to the rectus insertion, associated vitreoretinal trauma, optic nerve avulsion or transection, and extensive loss of intraocular contents all increase the likelihood of persistent NLP vision even after primary repair. ${ }^{19,22}$ Other clinical factors, such as the presence of light perception the first day after primary repair or presence of reversible pathology (such as widespread choroidal or dense vitreous and subretinal hemorrhage) increase the chance of visual recovery with additional surgeries. ${ }^{22}$ In our study, surgeons may have been more likely to choose primary enucleation/evisceration over primary repair in patients with NLP vision who were elderly, had more serious systemic comorbidities, and had severe ocular injuries where visual recovery was unlikely.

Patients with any potential for vision should receive globe-sparing procedures in hopes of retaining functional acuity. Primary repair in severe injuries should also be performed when patient disorientation post-trauma limits visual acuity assessment and informed consent, as well as when the psychological trauma of potential enucleation/ evisceration is too great for the patient to agree to initially. ${ }^{23}$ However, patients who undergo globe-sparing procedures may experience persistent pain or cosmetic disfigurement and eventually undergo secondary enucleation/evisceration as a result. In our study, intractable pain was overwhelmingly the most common reason for secondary eye removal (95.7\%). A previous review of 107 cases reported that $12 \%$ of patients with primary open globe injury repair eventually undergo secondary enucleation/ evisceration, with poor initial visual acuity, presence of 
RAPD or retinal detachment, and absence of a red reflex predicting secondary removal. ${ }^{24}$

In our study, all patients who underwent secondary removal had at least one preceding procedure, with $25 \%$ of patients experiencing at least one ocular complication, including infection, hemorrhage, choroidal or retinal detachment or tear, glaucoma, and wound dehiscence. There are important psychosocial factors that accompany repeated procedures in patients with ocular trauma. It has been demonstrated previously that patients with a history of ocular trauma have been shown to have higher rates of depression and anxiety when compared to the general population. ${ }^{2-4}$ While extra time between injury and enucleation/evisceration in patients who undergo secondary enucleation/evisceration may give patients more time to come to terms with their expected visual and cosmetic outcomes, an advantage of primary enucleation/evisceration is that it both prevents potential complications from repeated globe-sparing procedures on a blind eye and may also shorten the emotional distress that these patients endure.

Primary enucleation $(56 \%)$ was more common than primary evisceration (44\%) in our study. This may have occurred because, in the past, primary enucleation has often been cited to eliminate the risk of sympathetic ophthalmia. ${ }^{23}$ Although no patients in our study experienced sympathetic ophthalmia, it has been reported to occur in between $0.2 \%$ and $0.5 \%$ of eyes after penetrating ocular trauma and can happen as early as days after trauma. ${ }^{25-27}$ There is a theoretical increased risk of sympathetic ophthalmic after evisceration compared to enucleation due to the amount of ocular tissue retained; however, this theory is still strongly debated in the literature and warrants further research. ${ }^{28}$ Regardless, the improvement in immunosuppressive therapies available has decreased the use of this argument for primary enucleation in recent years.

Secondary enucleation (74.6\%) was also more common than secondary evisceration $(25.4 \%)$ in our cohort. Again, this finding may be influenced by the surgeon's desire to reduce the risk of sympathetic ophthalmia. Sympathetic ophthalmia usually occurs between 2 weeks and 2 months after trauma, leading to the controversial target to remove the eye within 2 weeks of injury. ${ }^{25-27,29}$ In our cohort, the median time to secondary eye removal was 34 days. However, many factors may influence a surgeon's decision to consider eye removal after 2 weeks. For example, the ophthalmologist may pursue eye removal in patients who develop eye pain or visual deterioration at some point after 2-weeks post-injury. Ultimately, because sympathetic ophthalmia can develop at any time after ocular injury, eye removal beyond 2 weeks will still reduce this risk. Aside from sympathetic ophthalmia considerations, enucleation may also be selected when the trauma to the scleral shell is so severe that evisceration would be extremely difficult. In addition, some literature suggests that enucleation results in better pain control and less post-operative pain than evisceration. ${ }^{30-32}$ However, one study found that complete pain relief was ultimately achieved in all patients who underwent enucleation or evisceration, at an average of 3 months after eye removal. ${ }^{33}$ A retrospective study found that both enucleation and evisceration lead to aesthetically similar outcomes. ${ }^{34}$ Eviscerated eyes may have improved implant motility, but not prosthetic motility, which often is more important to patients. ${ }^{34}$ Differences in complication rates between the two procedures are variable depending on the study and may be influenced more by the severity of injury than the type of procedure. ${ }^{34-36}$ Surgeon preference and experience likely plays a large role in deciding between enucleation or evisceration in severe ocular trauma.

The main limitation of our study is that it is a retrospective, single-center investigation. Because the study was done at a single center, the practice of primary versus secondary eye removal and the decision between enucleation or evisceration may depend on the views of a small number of oculoplastics faculty at our institution. The statistical power of our study was also limited by the small sample size. Future multicenter studies may be useful to define in which situations primary eye removal should be considered in the setting of severe eye trauma, and whether enucleation or evisceration is appropriate. Ultimately, this decision should be shared between the patient and the physician, taking into account patient factors as well as injury severity.

Our study also has several strengths and key findings that contribute to the field of ocular trauma research. The study took place at a designated eye trauma center, allowing for a cohort that was racially diverse, which included similar percentages of African-American/black and Caucasian/white patients. These patients presented over a period of 8 years, expanding the range of practice patterns employed by a variety of physicians. Lastly, we had a long duration of follow-up for the patients, allowing us to collect data about complications that occurred even years after the trauma. 


\section{Conclusion}

In our study, secondary eye removal was more common than primary eye removal after severe ocular trauma, and enucleation was employed more often than evisceration. Ultimately, additional research can help guide clinicians in shared decision making for situations in which primary enucleation/evisceration may be appropriate.

\section{Funding}

There is no extramural funding source supporting this investigation.

\section{Disclosure}

Dr. Nicholas R Mahoney reports that he had been on an advisory board with Horizon Therapeutics and that he provides consulting services for Guidepoint, outside the submitted work .

Dr Divya Srikumaran reports being a consultant for Alcon, grants from NEI, non-financial support from AAO Hoskins Center Grant, outside the submitted work. The authors report no other potential conflicts of interest in this work.

\section{References}

1. Kuhn F, Morris R, Witherspoon CD, Mann L. Epidemiology of blinding trauma in the United States Eye Injury Registry. Ophthal Epidemiol. 2006;13(3):209-213. doi:10.1080/09286580600665886

2. Yuksel H, Turkcu FM, Ahin M, et al. Vision-related quality of life in patients after ocular penetrating injuries. Arq Bras Oftalmol. 2014;77 (2):95-98. doi:10.5935/0004-2749.20140024

3. Alexander DA, Kemp RV, Klein S, Forrester JV. Psychiatric sequelae and psychosocial adjustment following ocular trauma: A retrospective pilot study. Brit $J$ Ophthalmol. 2001;85(5):560-562. doi:10.1136/ bjo.85.5.560

4. Ye J, Lou L, Kin K, et al. Vision-related quality of life and appearance concerns are associated with anxiety and depression after eye enucleation: A cross-sectional study. PLoS One. 2015;10(8):e0136460. doi:10.1371/journal.pone. 0136460

5. Kuhn F, Maisiak R, Mann L, Mester V, Morris R, Witherspoon CD. The Ocular Trauma Score (OTS). Ophthalmol Clin of North Am. 2002;15(2):163-165. doi:10.1016/S0896-1549(02)00007-X

6. McAlinden C, Saldanha M, Laws D. Evisceration for the management of ocular trauma. BMJ Case Rep. 2013;2013:bcr2013201235. doi:10.1136/bcr-2013-201235

7. Scott R. The Ocular Trauma Score. Community Eye Health. 2015;28 (91):44-45.

8. Gervasio KA, Weinstock BM, Wu AY. Prognostic value of ocular trauma scores in patients with combined open globe injuries and facial fractures. Am J Ophthalmol. 2015;160(5):882-888. doi:10. 1016/j.ajo.2015.08.007

9. Cillino S, Casuccio A, Di Pace F, Pillitteri F, Cillino G. A five-year retrospective study of the epidemiological characteristics and visual outcomes of patients hospitalized for ocular trauma in a Mediterranean area. BMC Ophthalmol. 2008;8(1):6. doi:10.1186/ 1471-2415-8-6
10. Wong TY, Tielsch JM. A population-based study on the incidence of severe ocular trauma in Singapore. Am J Ophthalmol. 1999;128 (3):345-351. doi:10.1016/S0002-9394(99)00167-1

11. Andreoli MT, Andreoli CM. Geriatric traumatic open globe injuries. Ophthalmology. 2011;118(1):156-159. doi:10.1016/j.ophtha.2010.04. 034

12. Oiticica-Barbosa MM, Kasahara N. Eye trauma in children and adolescents: perspectives from a developing country and validation of the Ocular Trauma Score. J Trop Pediatr. 2015;61(4):238-243. doi:10.1093/tropej/fmv010

13. Savar A, Andreoli MT, Andreoli CM, Kloek CE, Rubin AD. Enucleation after traumatic open globe: the massachusetts eye and ear infirmary experience. Invest Ophthalmol Vis Sci. 2007;48 (13):5483.

14. Soni NG, Bauza AM, Son JH, Langer PD, Zarbin MA, Bhagat N. Open globe ocular trauma: functional outcome of eyes with no light perception at initial presentation. Retina. 2013;33(2):380-386. doi:10.1097/IAE.0b013e318263cefb

15. Katz J, Tielsch JM. Lifetime prevalence of ocular injuries from the baltimore eye survey. Arch of Ophthalmol. 1993;111(11):1564-1568. doi:10.1001/archopht.1993.01090110130038

16. $\mathrm{CPT}^{\circledR}$ overview and code approval. American medical association; 2020. Available from: https://www.ama-assn.org/practicemanagement/cpt/cpt-overview-and-code-approval. Accessed June 5, 2020.

17. Savar A, Andreoli MT, Kloek CE, Andreoli CM. Enucleation for open globe injury. Am J Ophthalmol. 2009;147(4):595-600.

18. Walsh MT. Improving outcomes in ambulatory anesthesia by identifying high risk patients. Curr Opin Anaesthesiol. 2018;31 (6):659-666. doi:10.1097/ACO.0000000000000653

19. Agrawal R, Wei HS, Teoh S. Predictive factors for final outcome of severely traumatized eyes with no light perception. $B M C$ Ophthalmol. 2012;12:16. doi:10.1186/1471-2415-12-16

20. Han YS, Kavoussi SC, Adelman RA. Visual recovery following open globe injury with initial no light perception. Clin Ophthalmol. 2015;9:1443-1448. doi:10.2147/OPTH.S87852

21. Feng K, Hu YT, Ma Z. Prognostic indicators for no light perception after open-globe injury: eye injury vitrectomy study. $\mathrm{Am}$ J Ophthalmol. 2011;152(4):654-662. doi:10.1016/j.ajo.2011.04.004

22. Bhagat N, Turbin R, Langer $P$, et al. Approach to management of eyes with no light perception after open globe injury. $J$ Ophthalmic Vis Res. 2016;11(3):313-318.

23. Rahman I, Maino A, Devadason D, Leatherbarrow B. Open globe injuries: factors predictive of poor outcome. Eye. 2006;20 (12):1336-1341. doi:10.1038/sj.eye.6702099

24. Moshfeghi DM, Moshfeghi AA, Finger PT. Enucleation. Surv Ophthalmol. 2000;44(4):277-301. doi:10.1016/S0039-6257(99)001 12-5

25. Arevalo JF, Garcia RA, Al-Dhibi HA, Sanchez JG, Suarez-Tata L. Update on sympathetic ophthalmia. Middle East Afr J Ophthalmol. 2012;19(1):13-21.

26. Kilmartin DJ, Dick AD, Forrester JV. Prospective surveillance of sympathetic ophthalmia in the UK and Republic of Ireland. Brit J Ophthalmol. 2000;84(3):259-263. doi:10.1136/bjo.84.3.259

27. Zhang Y, Zhang MN, Jiang CH, Yao Y. Development of sympathetic ophthalmia following globe injury. Chin Med J. 2009;122(24): 2961-2966.

28. Chu XK, Chan CC. Sympathetic ophthalmia: to the twenty-first century and beyond. $J$ Ophthalmic Inflamm Infect. 2013;3:49. doi:10.1186/1869-5760-3-49

29. Makley TA, Azar A. Sympathetic ophthalmia. A long term follow up. Arch Ophthalmol. 1978;96:257-262. doi:10.1001/archopht.1978.039 10050125004

30. Custer PL, Reistad CE. Enucleation of blind, painful eyes. Ophthal Plast Reconstr Surg. 2000;16:326-329. doi:10.1097/00002341-2000 09000-00004 
31. Calenda E, Retourt A, Muraine M. Is evisceration of the eye more painful than enucleation? Eur J Anesthesiol. 1999;16(2):117. doi:10.1046/j.1365-2346.1999.00434.x

32. Pai-Dei Chen W. Enucleation, evisceration and exenteration. In: Oculoplastic Surgery. McCord CD, Tanenbaum M, Nunery WR, editors. 3rd ed. New York: Raven Press; 1995:Chapter 19.

33. Shah-Desai SD, Tyers AG, Manners RM. Painful blind eye: efficacy of enucleation and evisceration in resolving ocular pain. $\mathrm{Br}$ J Ophthalmol. 2000;84(4):437-438. doi:10.1136/bjo.84.4.437

34. Nakra T, Simon GJB, Douglas RS, Schwarcz RM, McCann JD, Goldberg RA. Comparing outcomes of enucleation and evisceration. Ophthalmology. 2006;113(12):2270-2275. doi:10.10 16/j.ophtha.2006.06.021
35. Zheng $\mathrm{C}$, Wu AY. Enucleation versus evisceration in ocular trauma: A retrospective review and study of current literature. Orbit. 2013;32 (6):356-361. doi:10.3109/01676830.2013.764452

36. Holmes CJ, McLaughlin A, Farooq T. Outcomes of ocular evisceration and enucleation in the british armed forces from Iraq and Afghanistan. Eye. 2019;33:1748-1755. doi:10.1038/s41433-019$0480-5$

\section{Publish your work in this journal}

Clinical Ophthalmology is an international, peer-reviewed journal covering all subspecialties within ophthalmology. Key topics include: Optometry; Visual science; Pharmacology and drug therapy in eye diseases; Basic Sciences; Primary and Secondary eye care; Patient Safety and Quality of Care Improvements. This journal is indexed on PubMed

Submit your manuscript here: https://www.dovepress.com/clinical-ophthalmology-journal
Central and CAS, and is the official journal of The Society of Clinical Ophthalmology (SCO). The manuscript management system is completely online and includes a very quick and fair peer-review system, which is all easy to use. Visit http://www.dovepress.com/ testimonials.php to read real quotes from published authors. 